\title{
A bellweather for climate change and disability: educational needs of rehabilitation professionals regarding disaster management and spinal cord injuries
}

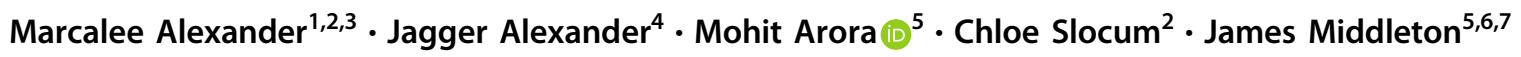

Received: 17 October 2019 / Accepted: 23 October 2019

(c) The Author(s), under exclusive licence to International Spinal Cord Society 2019

\begin{abstract}
Study design Cross-sectional survey.

Objective Persons with disabilities are disproportionately impacted by extreme weather disasters and climate change. Individuals with spinal cord injury (SCI) are especially at risk due to inability to control their body temperature and mobility concerns. We surveyed rehabilitation professionals in the field of SCI to determine their experiences, concerns and educational needs regarding natural disasters, climate change and sustainability and the effects on their clientele.
\end{abstract}

Setting Online survey available to an international cohort.

Methods The survey was developed by the authors and conducted in 2019. It was distributed amongst various international health care organizations whose members care for persons with SCI. Descriptive statistics and chi-square test for association were performed using Microsoft Excel 2016.

Results Of 125 respondents, 50\% were from Europe, 18\% from North America, and 18\% from Asia; $74 \%$ were physicians and $13 \%$ physical therapists. In total $57.6 \%$ believed climate change had impacted their client's health and well-being. Respondents from North America were significantly less likely to report climate change had an impact on their patient's health than those from Asia or Europe $(p<0.01)$. In total $82.5 \%$ of respondents thought professionals should be concerned with sustainability and $85.5 \%$ were interested in further education.

Conclusions Most respondents acknowledged a need for more information related to the disasters, climate change, and disability. Results underscore the need for further research, professional, and consumer education.

Marcalee Alexander

spinalcordmd@live.com

1 Department of Physical Medicine and Rehabilitation, University of Alabama at Birmingham School of Medicine, Birmingham, AL, USA

2 Department of Physical Medicine and Rehabilitation, Harvard School of Medicine, Spaulding Rehabilitation Hospital, Charlestown, MA, USA

3 Telerehabilitation International, Birmingham, AL, USA

4 Vanderbilt University, Nashville, TN, USA

5 John Walsh Centre for Rehabilitation Research, Sydney Medical School, Northern Clinical School, Faculty of Medicine and Health, The University of Sydney, Sydney, NSW, Australia

6 State Spinal Cord Injury Service, NSW Agency for Clinical Innovation, Sydney, NSW, Australia

7 NSW Spinal Outreach Service, Royal Rehab, Sydney, NSW, Australia

\section{Introduction}

Extreme weather events with prolonged exposure to heat or cold and natural disasters such as hurricanes, floods, wildfires, dust storms, and droughts are increasing in frequency in conjunction with the climate crisis [1]. Disasters affect communities and the people within them by disrupting the natural environment, manmade structures, and social environments. Persons with disabilities are disproportionately impacted by these disasters [2]. Individuals with spinal cord injury (SCI) are especially at risk due to relative immobility and potential dependence on others for self-care. Moreover, individuals with higher level SCI will have a core temperature that rises or lowers based upon the ambient temperature, [3] making them more vulnerable to extreme heat and cold. This will require them to stay indoors more frequently as climate change accelerates, likely undermining years of efforts that rehabilitation professionals have focused on community reintegration [4]. 
Increased morbidity and mortality are associated with disasters [5]. However, the day-to-day effects of climate change have been described as the biggest global health threat of the 21st century [1]. The ongoing general health effects of climate change include increases in incidence of infectious diseases such as dengue, malaria, salmonellosis, and hantavirus [6], as well as increased respiratory disorders [7], diarrheal illnesses [8], anxiety, and depression [9].

A number of international working groups are considering the issue of climate and health [1]; however, relatively little attention is paid to the issues of persons with disabilities and, in particular, persons with SCI. Disability and Climate Resilience, a recent literature review [10] noted that a recent Intergovernmental Panel on Climate Change, failed to mention people with disabilities. Information is also not being shared in accessible formats [11]. In contrast, there are a number of excellent papers written about the impact of earthquakes on persons with SCI [2, 12, 13].

In tandem with considering the impacts of climate change on persons with SCI, it is important to consider issues of sustainability and whether professionals consider sustainability in their practices. Moreover, telemedicine is promising as a sustainable means of assisting in the care of persons with SCI due to the ability to reach out to people living long distances away without adding to the carbon footprint. Patients have also generally given positive feedback on their experiences with telemedicine [14]. Considering the vulnerability of persons with SCI to natural disasters and climate change and the lack of information regarding sustainability practices in SCI, we conducted a survey assessing the relevant experiences, concerns, and educational needs of rehabilitation professionals working in the field of SCI.

\section{Methods}

\section{Study design}

The authors developed a survey to assess the experiences and educational needs of health care professionals working in the field of SCI regarding natural disasters, climate change, and sustainability. The survey was specifically designed to focus on determining the perceived changes and impacts of weather and climate in the professionals' locale, the effects of these changes on their clients, the professionals' perception of their own and their clients' abilities to address future concerns related to climate change and related educational needs. Once the survey was composed, it was uploaded online, tested, and then distributed amongst health care professional networks. This included members of the International Spinal Cord Society and other national organizations of professionals working in the field of SCI.
The survey was conducted between January and July 2019. As the primary nature of this survey was to determine educational needs, we did not obtain IRB approval for this survey.

\section{Statistics}

Descriptive statistics are provided for variables based upon continent. When comparing results between continents or climate, chi-square test for association was used. Statistics were performed using Microsoft Excel 2016. Groups where $n<9$ were not included in statistical analyses.

\section{Results}

\section{Participants}

Respondents included 125 rehabilitation professionals over six continents. Demographics are provided in Table 1.

Regarding local climate conditions, $48.0 \%$ reported they lived in a moderate climate, $19.2 \%$ reported they lived in a continental climate, $16.8 \%$ lived in a tropical climate, $6.4 \%$ lived in a dry climate, and $4.0 \%$ lived in a polar climate. The remainder of participants $(12.8 \%)$ were unsure. Most respondents $(59.2 \%)$ perceived the climate in their region had changed while $23.2 \%$ perceived it had not changed and $17.6 \%$ reported they were unsure. Respondents were asked whether they believed climate and weather changes influenced their SCI clients' health and well-being, with 57.6\% responding yes, $24.0 \%$ being unsure, and $18.4 \%$ saying no. There was no significant association between type of climate reported in participants' locale and participants' perception of whether the climate had changed over the past 5 years $\left(\chi^{2}=3.023, \mathrm{df}=4, p=0.55\right)$, nor was there a significant association between participants' continent of practice and their perception of whether the climate over the past 5 years had changed $\left(\chi^{2}=8.325, \mathrm{df}=4, p=0.08\right)$.

Similarly, there was no relation between type of climate reported in participants' locale and whether the climate had an impact on patients' health and well-being $\left(\chi^{2}=5.942\right.$, $\mathrm{df}=4, p=0.20$ ). There was, however, a significant association with participants' continent of practice and whether the respondents reported climate had an impact on their patients' health and well-being $\left(\chi^{2}=16.33, \mathrm{df}=4, p<0.01\right)$. Fewer respondents from North America reported that the climate had an impact on their client's health (30.4\%) in comparison with participants from Asia (82.6\%) or Europe (59.7\%).

Most respondents $(56.8 \%)$ reported that extreme heat spells had an impact on their clients' health in the past 5 years while other data is presented in Fig. 1. With regards to perception of how climate change had impacted their clients' health and well-being (Fig. 2), approximately half 
Table 1 Demographics

\begin{tabular}{|c|c|c|}
\hline Characteristic & $N$ & Percentage \\
\hline \multicolumn{3}{|l|}{ Age } \\
\hline $21-30$ & 10 & 8.0 \\
\hline $31-40$ & 24 & 19.2 \\
\hline $41-50$ & 32 & 25.6 \\
\hline $51-60$ & 45 & 36.0 \\
\hline $61-70$ & 12 & 9.6 \\
\hline $71-80$ & 1 & 0.8 \\
\hline$>80$ & 1 & 0.8 \\
\hline \multicolumn{3}{|l|}{ Continent } \\
\hline Europe & 62 & 49.6 \\
\hline Asia & 23 & 18.4 \\
\hline North America & 23 & 18.4 \\
\hline Oceania & 9 & 7.2 \\
\hline South America & 4 & 3.2 \\
\hline Africa & 4 & 3.2 \\
\hline \multicolumn{3}{|l|}{ Profession } \\
\hline Medical Doctor & 93 & 74.4 \\
\hline Physical Therapy & 16 & 12.8 \\
\hline Nursing & 4 & 3.2 \\
\hline Psychology & 3 & 2.4 \\
\hline Researcher & 5 & 4.0 \\
\hline Other $^{\mathrm{a}}$ & 4 & 3.2 \\
\hline \multicolumn{3}{|c|}{ Years worked in health care } \\
\hline $0-10$ & 21 & 16.8 \\
\hline $11-20$ & 34 & 27.2 \\
\hline $21-30$ & 37 & 29.6 \\
\hline $31-40$ & 29 & 23.2 \\
\hline $41-50$ & 3 & 2.4 \\
\hline $51-60$ & 1 & 0.8 \\
\hline \multicolumn{3}{|l|}{ Work setting } \\
\hline Private & 39 & 31.2 \\
\hline Public & 54 & 43.2 \\
\hline Private/public & 24 & 19.2 \\
\hline Other $^{\mathrm{b}}$ & 8 & 6.4 \\
\hline \multicolumn{3}{|l|}{ Patient population } \\
\hline Privileged $^{\mathrm{c}}$ & 79 & 63.2 \\
\hline Underprivileged $^{\mathrm{d}}$ & 40 & 32.0 \\
\hline Combined & 4 & 3.2 \\
\hline Other & 3 & 2.4 \\
\hline \multicolumn{3}{|l|}{ Work location } \\
\hline City & 104 & 83.2 \\
\hline Country & 15 & 12.0 \\
\hline Suburb & 6 & 4.8 \\
\hline
\end{tabular}

${ }^{\mathrm{a}}$ Medical student $=1$, manager $=1$, physiotherapist advisor to $\mathrm{NGO}=$ 1 , government employee $=1$

${ }^{\mathrm{b}}$ University hospital $=1$, academic $=2, \mathrm{NGO}=3$, charity $=1$, veterans $=1$

${ }^{c}$ Most patients have access to vehicles, electricity, and adequate equipment

${ }^{\mathrm{d}}$ Many patients do not have access to vehicles, electricity, or basic equipment

of respondents $(47.2 \%)$ acknowledged problems with temperature control while $41.6 \%$ noted increased fatigue, $40.0 \%$ noted breathing problems, and $37.6 \%$ acknowledged issues with dehydration.
Provider Perceptions of Climactic Conditions Impacting Health of Persons with SCls $(\mathrm{N}=125)$

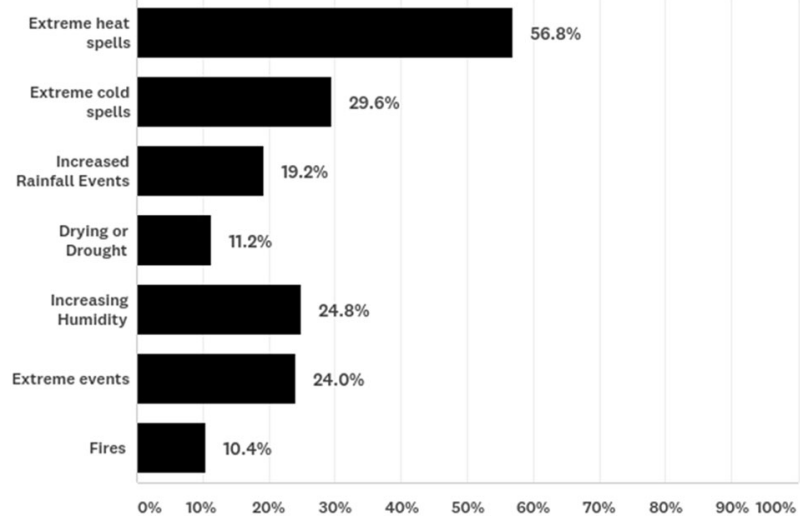

Fig. 1 Perceptions of respondents on events impacting their clients

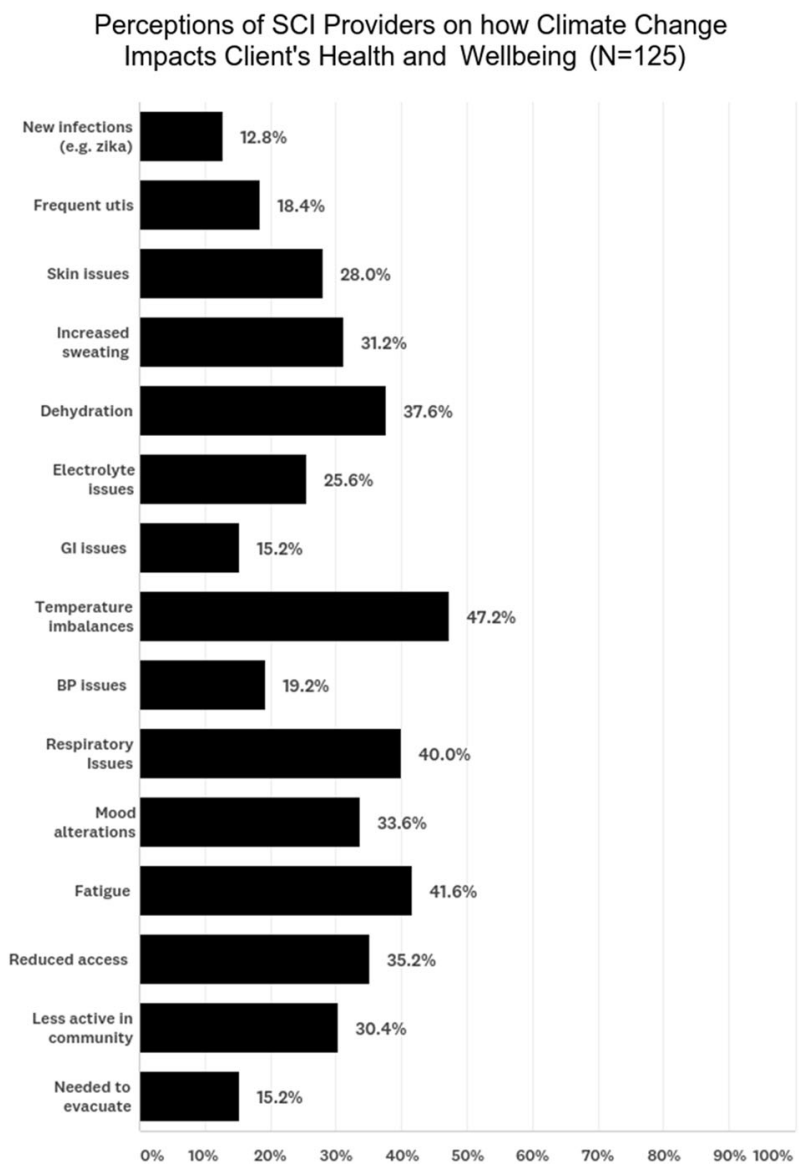

Fig. 2 Perceptions of respondents on how climate change impacts their clients

The results of which issues respondents usually addressed with their clients are presented in Fig. 3. Most respondents $(64.8 \%)$ acknowledged addressing the need to maintain adequate fluid intake and the need for heat 
Climate and health issues providers address with clients with $\mathrm{SCls}(\mathrm{N}=125)$

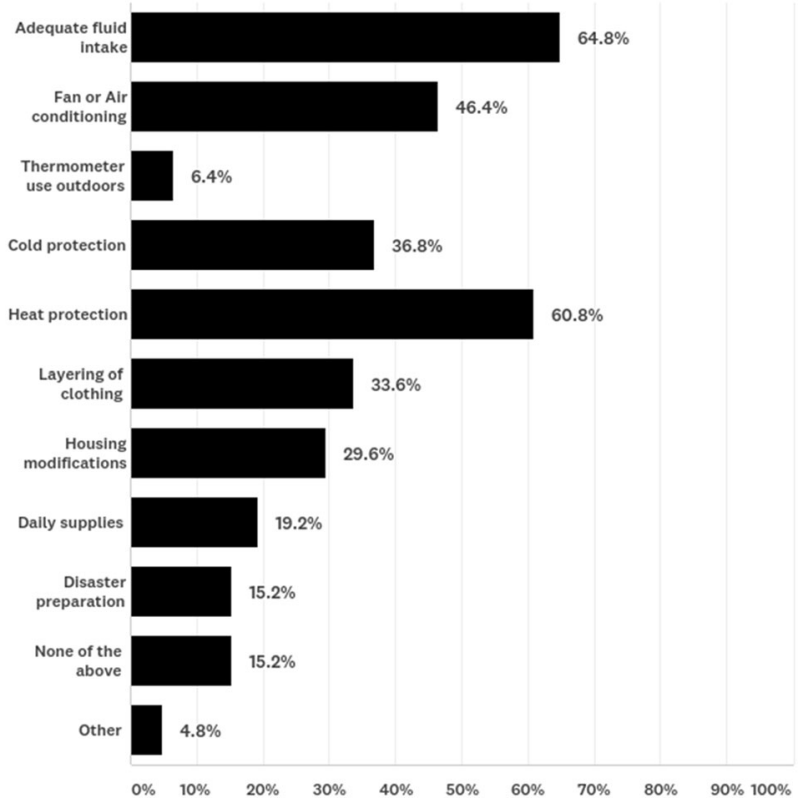

Fig. 3 Percentage of respondents acknowledging addressing specific climate and health issues with clients with SCIs

protection $(60.8 \%)$. Interestingly, $15.2 \%$ did not routinely address any of these concerns.

While $50.4 \%$ of respondents had not experienced disasters in their region related to weather/climate, $31.2 \%$ reported they had experienced low impact disasters, $11.2 \%$ had experienced moderate impact disasters, and $7.2 \%$ had experienced high impact disasters. Most professionals $(75.2 \%)$ reported they had not taken action to educate patients regarding disaster preparation while $24.8 \%$ reported they had.

With regards to solutions and concerns, respondents were queried as to whether they had used telemedicine to assist with access difficulties due to weather or disasters. The vast majority $(72.0 \%)$ reported they had not, $17.6 \%$ reported they use telemedicine for emergencies and routine practice, and $10.4 \%$ said they use telemedicine for emergencies. Of respondents, most $(76.8 \%)$ were interested to learn more about telemedicine, while $20.8 \%$ were not interested.

An overwhelming majority (82.4\%) of respondents thought professionals should be concerned about sustainability; however, $15.2 \%$ of respondents were unsure and $2.4 \%$ did not think professionals should concern themselves with sustainability. In total $64.8 \%$ of respondents indicated that they considered sustainability when caring for and prescribing supplies/equipment for their patients with SCI, while the rest did not.

On a scale of $0-10(0=$ not at all; $10=$ completely prepared) respondents were asked how they perceive their own readiness to address the impact of climate change and
Areas respondents believe would be most useful to develop for educational purposes $\mathrm{N}=125$

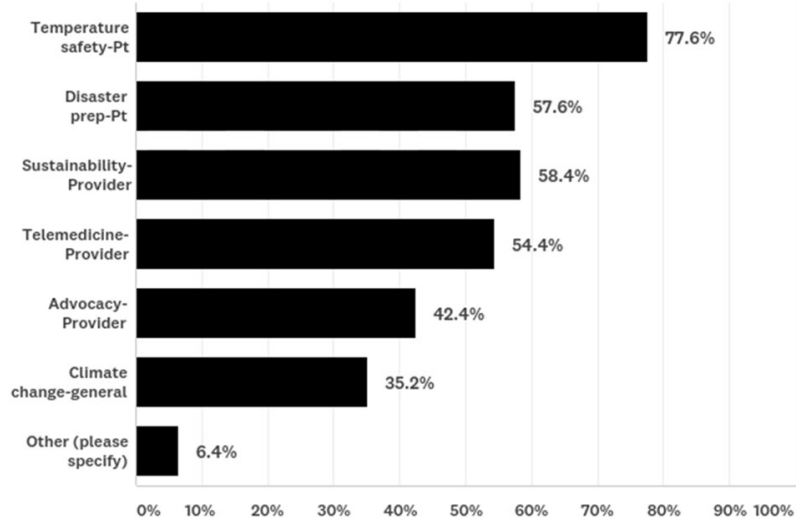

Fig. 4 Areas of educational development endorsed by respondents

natural disasters on their patient's health in the future. The mean response was 3.16 with an SD of 2.19. Moreover, respondents were queried as to how prepared they perceived their patients are to respond to the impacts of extreme weather events and climate change, the mean score was a 2.55 with a SD of 1.94 .

Most respondents (85.5\%) were interested in learning more about extreme weather and climate concerns for their clients with SCI. Specific educational recommendations are presented in Fig. 4; however, the majority $77.6 \%$ recommended development of materials related to patient safety in extreme heat and cold. In addition, over $50 \%$ of respondents were interested in information for their patients on disaster preparation, practicing sustainability in health care, and on telemedicine.

Respondents were also asked to provide their general comments at the end of the survey. The common themes evolved from the comments were "Telemedicine a potential as intervention", "Access to information", "Climate change and Education: A very important topic", "This should be a part of comprehensive management", and "Government support". Some quotes from the respondents are as below:

"We need the help of the state, political will and assistance...."

"Need for telemedicine"

"I would like to have more telemedicine information"

"SCI patients have to be well informed regarding the impact of temperature changes in their body." 


\section{Discussion}

Our results provide an initial snapshot of the perceptions of professionals working in SCI regarding the impact of disasters and climate change in their locale on their clients. Most respondents perceived that the climate in their region had changed; moreover, this did not differ based on type of climate or continent. Interestingly, participants from North America were significantly less likely to perceive that the climate had an impact on their client's health than participants from Europe or Asia and one must wonder whether this is as a result of a different perception of climate change in the US, sampling bias or whether other factors are at play, such as practitioners in cities being less impacted by disasters and climactic events than practitioners who work in coastal areas. This difference is important when considering the development of educational tools as those providers who already acknowledge the impact of climate on their clients will be more likely to engage in educational activities than those who do not acknowledge this concern.

A variety of areas were acknowledged as being clinical concerns regarding climate change including temperature imbalances, respiratory issues, and fatigue; and these bear consideration in clinicians' regular practice and rehabilitation programming. Moreover, other issues such as reduced access, less community activity, and mood alterations were affirmed. These issues are of concern because they have potential to negatively impact the day-to-day quality of life of persons with SCI. Climate change has been linked to depression and anxiety in the general population [9] and we can anticipate that persons with SCI will experience the general increase in mood problems. However, the potential for temperature imbalance and fatigue will lead to an inability to pursue community activities and ultimately persons with SCI may become "climate-jailed" and forced to remain indoors for long periods of time due to weather extremes, which could lead to even greater morbidity from depression in persons with SCI.

Education of providers and persons with $\mathrm{SCI}$ is important to ensure concerns regarding climate change are appropriately acknowledged and addressed. The area respondents recommended for development the most is patient education regarding temperature safety followed by disaster preparation information for patients. This type of information is necessary to develop in regional formats and could be provided in an online format. In addition, greater efforts can be made to incorporate these activities into inpatient rehabilitation. Over $50 \%$ of providers were interested in further information on sustainability and telemedicine, approximately $40 \%$ were interested in information regarding advocacy and $35 \%$ would like more information on climate change in general. These results underscore the need for continuing education for rehabilitation professionals to be comprehensive and not just focused on medical concerns and demonstrates the critical importance of incorporating climate change and its effects on health for people with SCI into conference programming for professionals at the local, regional, national, and international levels.

Issues of sustainability should be discussed in tandem with the impact of climate change on persons with SCI. Daily needs of persons with SCI result in the use of disposable supplies, the need for specialized transportation, and equipment that may require electricity. While most respondents reported considering sustainability in routine practice, $30 \%$ of respondents said they did not. One means of promoting sustainability in the care of persons with SCI is the use of "telespinalcordinjury" [14]. By its nature, telemedicine results in a decrease in miles a client must travel to see a practitioner and results in saving of energy, a decrease in carbon emissions, and time spent traveling to appointments and is, as a result, cost saving. While only $17.6 \%$ of respondents indicated they actively used telemedicine to care for their clients, another $10.4 \%$ acknowledged use in emergency situations and $76.8 \%$ expressed interest in further education; thus, this is an important area for development of educational programming.

This survey must be considered as a pilot and has several limitations. There is potential bias as providers with a greater interest in climate change may have been more apt to respond. There were fewer respondents from certain continents, specifically Oceania, Africa, and South America, including areas with higher incidences of poverty, to truly compare the issues on all continents. Instead of relying on standardized data regarding climate change, this survey relied on providers' perceptions of the whether their locales had a change in climate within the past 5 years. Finally, in this survey we did not ask individuals with SCI about their own perceptions of how the climate has affected them. Nevertheless, we believe the information is useful as a starting point for international educational tools.

This is a preliminary survey addressing a sample of professionals regarding SCI; nevertheless, the multiple ways people with SCI can be affected by climate change make consideration of their concerns a bellwether for the problem of climate change in the overall population of people with disabilities. Further research regarding climate change and disability, in particular SCI, is necessary. Of note, the United Nations recently passed a resolution declaring the issues of climate change and disability as a human rights concern in July 2019 [15]. Thus, we are optimistic that the importance of addressing this topic will be acknowledged in more national and international forums. In sum, issues related to SCI and climate change are important topics for further discussion and research. Our results underscore the need for continuing education offerings and accessible consumer education materials. 


\section{Compliance with ethical standards}

Conflict of interest MA is CEO of Telerehabilitation International-a NGO that is being formed and has fund-raised for United Spinal Association and Portlight Disaster Strategies regarding disasters, climate change, and spinal cord injuries. The remaining authors declare that they have no conflict of interest.

Ethical approval We certify that all applicable institutional and governmental regulations concerning the ethical use of human volunteers/ animals were followed during the course of this research.

Publisher's note Springer Nature remains neutral with regard to jurisdictional claims in published maps and institutional affiliations.

\section{References}

1. Watts N, Amann M, Arnell N, Ayebb-Karlsson S, Belesova K, Berry H, et al. The 2018 report of the Lancet Countdown on health and climate change: shaping the health of nations for centuries to come. Lancet. 2018;392:2479-514.

2. Gaskin C, Taylor D, Kinnear S, Mann J, Hillman W, Moran M. Factors associated with the climate change vulnerability and the adaptive capacity of people with disability: a systematic review. Weather Clim Soc. 2017;9:801-14.

3. Burns A, O'Connell C, Rathore F. Meeting the challenges of spinal cord injury care following sudden onset disaster-Lessons learned. J Rehabil Med. 2012;44:414-20.

4. De Vivo MJ, Richards JS. Community reintegration and quality of life following spinal cord injury. Paraplegia. 1992;30:108-12.

5. Bourque L, Siegel J, Kano M, Wood M, Rodríguez H, Quarantelli E, et al. Morbidity and mortality associated with disasters. 2009. https://doi.org/10.1007/978-0-387-32353-4_6.
6. Wu X, Lu Y, Zhou S, Chen L, Xu B. Impact of climate change on human infectious diseases: empirical evidence and human adaptation. Environ Int. 2016;86:14-23.

7. D'Amato G, Vitale C, DeMartino A, Viegi G, Lanza M, Molino A, et al. Effects on asthma and respiratory allergy of climate change and air pollution. Multidiscip Respiratory Med. 2015;10:1-8.

8. Azage M, Kumie A, Worku A, Bagtzoglou A, Anagnostu E. Effect of climate variability on childhood diarrhea and its high risk periods in northwestern parts of Ethiopia. PLoS ONE. 2017;12: $\mathrm{e} 0186933$.

9. Berry H, Bowen K, Kjellstrom T. Climate change and mental health: a causal pathways framework. Int $\mathrm{J}$ Public Health. 2010;55:123-32.

10. Smith F, Simard M, Twigg J, Kett M, Cole E. Disability and climate resilience: a literature review 2017. http://adaptation.ei. columbia.edu/files/2018/02/Disability-and-Climate-ResilienceLit-review-.pdf. Accessed 15 Oct 2019.

11. Wolbring G. A culture of neglect: climate discourse and disabled people. M/C J. 2009;12. ISSN 14412616. http://journal.mediaculture.org.au/index.php/mcjournal/article/view/173. Accessed 16 Oct 2019

12. Burns AS, O'Connell C, Landry M. Spinal cord injury in postearthquake Haiti: lessons learned and future needs. PMR. 2010;2:695-7.

13. Chen R, Song y, Kong Q, Zhou C, Liu L. Analysis of 78 patients with spinal injuries in the 2008 Sichuan, China, earthquake. Orthopedics. 2009;32:322-6.

14. Irgens I, Rekand T, Arora M, Liu N, Marshall R, BieringSorensen F, et al. TeleSCI/D-a systematic review and recommendations for development. Spinal Cord. 2018;56: 643-55.

15. Schulte C, Gazendam I. https://www.hrw.org/news/2019/07/15/ un-climate-resolution-emphasizes-protection-disability-rights. Accessed 7 Oct 2019 